\title{
Impact of COVID-19 on the Co-Movement of Cryptocurrencies and Financial Assets: Evidence from Malaysia
}

Pick-Soon Ling

To Link this Article: http://dx.doi.org/10.6007/IJARAFMS/v11-i3/10886 DOI:10.6007/IJARAFMS /v11-i3/10886

Received: 10 June 2021, Revised: 11 July 2021, Accepted: 29 July 2021

Published Online: 16 August 2021

In-Text Citation: (Pick-Soon Ling, 2021)

To Cite this Article: Pick-Soon Ling. (2021). Impact of COVID-19 on the Co-Movement of Cryptocurrencies and Financial Assets: Evidence from Malaysia. International Journal of Academic Research in Accounting Finance and Management Sciences, 11(3), 395-409.

Copyright: (C) 2021 The Author(s)

Published by Human Resource Management Academic Research Society (www.hrmars.com)

This article is published under the Creative Commons Attribution (CC BY 4.0) license. Anyone may reproduce, distribute, translate and create derivative works of this article (for both commercial and non-commercial purposes), subject to full attribution to the original publication and authors. The full terms of this license may be seen at: http://creativecommons.org/licences/by/4.0/legalcode

Vol. 11, No. 3, 2021, Pg. 395 - 409

Full Terms \& Conditions of access and use can be found at http://hrmars.com/index.php/pages/detail/publication-ethics 


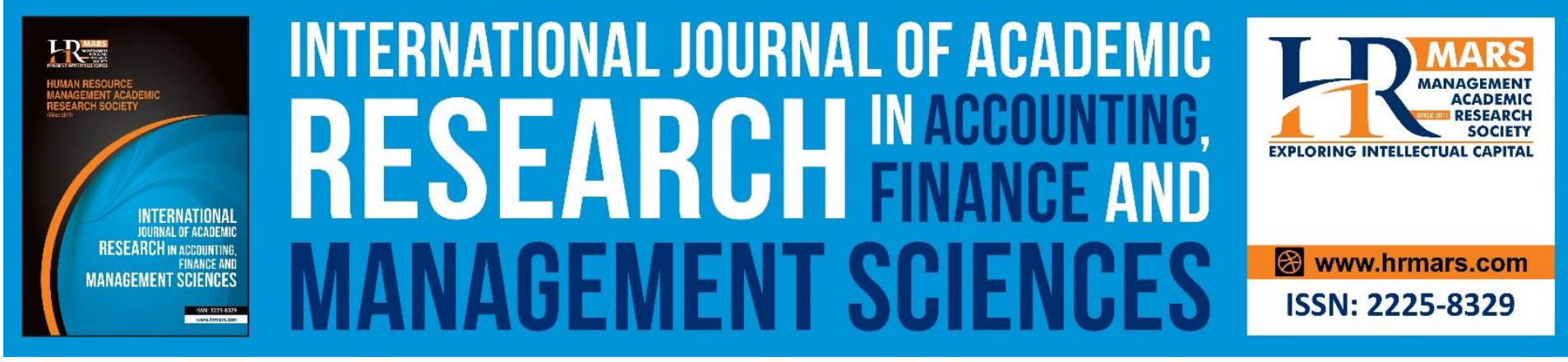

\title{
Impact of COVID-19 on the Co-Movement of Cryptocurrencies and Financial Assets: Evidence from Malaysia
}

\author{
Pick-Soon Ling \\ School of Business and Management, University College of Technology Sarawak, \\ 96000 Sibu, Sarawak, Malaysia, Centre on Technological Readiness and Innovation in \\ Business Technopreneurship, University College of Technology Sarawak, 96000 Sibu, \\ Sarawak, Malaysia \\ Email: ling.pick.soon@ucts.edu.my
}

\begin{abstract}
Due to the significant increase in novel coronavirus disease (COVID-19) cases in Malaysia, this study took the initiative to examine the impact of COVID-19 on the co-movement of five selected cryptocurrencies and two financial assets, namely FTSE Bursa Malaysia Kuala Lumpur Composite Index (FBMKLCl) and Ringgit Malaysia over United States Dollar (MYRUSD). By using the daily frequency data from May 2013 to July 2021, the Dynamic Conditional Correlation of Multivariate GARCH (MGARCH-DCC) was applied to examine the time-varying conditional correlation of these financial assets as it could determine the co-movement of the assets. Then, independent t-test and non-parametric Mann-Whitney $U$ test were utilised to examine the conditional correlation difference from the pre-COVID-19 pandemic and during the COVID-19 pandemic period. The results of the independent t-test and Mann-Whitney $U$ test proved that the co-movements of the cryptocurrencies and FBMKLCl and MYRUSD had significant differences after the COVID-19 pandemic outbreak in Malaysia. This implied that co-movement between the cryptocurrencies and FBMKLCl and MYRUSD was impacted by the COVID-19 pandemic as it was strengthened during the COVID-19 pandemic period, except for Binance and Cardano with $\mathrm{FBMKLCl}$, which showed a weakened co-movement during the COVID-19 pandemic period. These findings provided a crucial implication for all stakeholders as the findings could be used as guidance in reallocating the investment portfolio, especially during the COVID-19 pandemic period.
\end{abstract}

Keywords: Co-Movement, COVID-19, Cryptocurrencies, Malaysian Stock Market, MGARCHDCC

\section{Introduction}

At the end of 2019, the first novel coronavirus disease (COVID-19) was reported in Wuhan, China and soon after that, the disease spread worldwide. Thailand reported the first confirmed case outside of China on 13 January 2020 (Shah et al. 2020). The disease was expected to have a huge impact on the world's economy, especially in the financial markets. 
MANAGEMENT SCIENCES

Vol. 11, No. 3, 2021, E-ISSN: 2225-8329 @ 2021 HRMARS

As mentioned by $\mathrm{He}$ et al. (2020), COVID-19 pandemic has a remarkable effect on the economies of affected countries. The economic growth and development of economies were threatened by the COVID-19 pandemic, especially in developing economies that have inadequate healthcare systems, insufficient resources and others (Takyi and Bentum-Ennin, 2021). In the financial market, this COVID-19 pandemic was also assumed as a "Black Swan" event, which will lead to a negative shock on the financial markets and the investors will fear the event (Hassan et al., 2021). Moreover, this "Black Swan" event could increase the market uncertainty, and investors tend to react negatively by withdrawing their investments from the stock markets. Therefore, the financial markets are expected to react negatively to this kind of event and it is acknowledged in many studies (Chen et al., 2007; Tavor and TeitlerRegev, 2019; Feng and Li, 2021).

Similarly, the Malaysian stock market also responded adversely to the COVID-19 pandemic as the market index dropped significantly (Lee et al., 2020). As one of the emerging markets that relied on international trade, Malaysia was also impacted by this disease after the first confirmed COVID-19 case was reported on 25 January 2020 (Shah et al., 2020). The scenario became worse in March 2020 because some of the new confirmed cases were found to have attended different meetings or gatherings, and thus the new confirmed cases increased significantly. To break the virus transmission within the country, the Malaysian Government implemented several restrictions, including limited or forbade flights and travellers from China, declared the implementation of a movement control order (MCO), and banned foreigners from entering the country. These restrictions had a great influence on the national economics, especially in tourism, airlines, food and beverages, and other related industries. The stock market responded immediately after those restrictions were announced as the prospect revenue and profit of particular stocks in affected industries declined dramatically. Several countries also implemented similar restrictions. Moreover, the "lockdown" had impacted the international financial market stability (Melki and Nefzi, 2021).

The COVID-19 pandemic also affected the stability of cryptocurrency markets and increased market volatility (Lahmiri and Bekiros 2020). As mentioned by Umar et al. (2021), the cryptocurrency market was significantly impacted by the COVID-19 pandemic as the market experienced a substantial sale of cryptocurrencies. Then, the total market capitalisation of the cryptocurrency market resulted in a dramatic dropped and caused "Black Monday" in the stock market (Umar et al., 2021). Several studies were conducted to explore the effect of COVID-19 pandemic on the cryptocurrency market. For instance, Conlon and McGee (2020) and Corbet et al. (2020) revealed that there was no safe-haven benefit provided by bitcoin on the stock markets during the COVID-19 pandemic. However, Corbet et al (2020); Corbet et al., (2021) suggested that cryptocurrencies could be a good safe-haven instrument during the COVID-19 pandemic period. These unconvincing findings had raised interest in the COVID-19 pandemic impact on the co-movement between the cryptocurrencies and traditional financial markets as some studies found that cryptocurrencies were effective safe-haven and/or hedging instruments for traditional financial markets, but some discovered otherwise. This was consistent with the argument, whereas the impact of COVID-19 pandemic on the economy is still under debate (He et al. 2020). Theoretically, if the cryptocurrency is likely to be highly correlated with another traditional financial instrument, it indicates that the cryptocurrency does not provide such diversification benefit or behave as a safe-haven for those traditional financial markets. This is relatively important for the "Black Swan" events such as the COVID-19 pandemic as stakeholders have to know if the cryptocurrencies could provide such benefit for them to 
MANAGEMENT SCIENCES

Vol. 11, No. 3, 2021, E-ISSN: 2225-8329 @ 2021 HRMARS

reallocate their investment portfolio to mitigate the COVID-19 pandemic impact on traditional financial markets. For that reason, this study is intended to achieve the following objectives:

- To examine the impact of the COVID-19 pandemic on the co-movement between five selected cryptocurrencies and the Malaysian stock market index (FBMKLCl); and

- To examine the impact of the COVID-19 pandemic on the co-movement between five selected cryptocurrencies and the foreign exchange rate (MYRUSD).

This study offers some contributions. Firstly, studies which examined the impact of COVID-19 pandemic on the co-movement between cryptocurrencies and financial markets by comparing the pre-COVID-19 and during COVID-19 are lacking. Most of current studies have investigated the property of hedge and/or the safe-haven of cryptocurrencies on the financial markets during this pandemic period. Moreover, most previous studies investigated the context by using developed market samples. Therefore, this study provides new evidence in literature, especially on the investment and portfolio management by examining the topic from the developing market perspective such as Malaysia. Malaysia is one of the heavily impacted markets by the COVID-19 pandemic. Therefore, it is essential to discover such a shock on the co-movement between the cryptocurrency and financial markets as it could provide a crucial implication to stakeholders.

\section{Literature Review}

Many studies empirically examined the impact of several international events on financial markets such as terrorisms, natural disasters, public health pandemics, and others (Ferreira and Karali 2015; Scholtens and Voorhorst 2013; Tavor and Teitler-Regev 2019; Feng and Li2021; Chen et al., 2007). For instance, Chensney et al (2011) concluded that terrorist events have a significant negative effect on stock markets. Scholtens and Voorhorst (2013) revealed that earthquakes have significantly negative impacts on stock market. Ferreira and Karali (2015) found that financial markets are marginally impacted by the earthquake shocks as most markets had zero returns. Tavor and Teitler-Regev (2019) found that disasters and terrorisms had a bad impact on the stock market, especially on the day of the events. Similarly, the negative impact of SARS on stock markets was also acknowledged in some studies (Chen et al., 2007; Feng and Li, 2021). Therefore, these international events possess a huge influence on the financial markets, including stock markets, commodities markets, cryptocurrencies markets and others.

By focusing on the stock markets, Liew (2020) found that the COVID-19 pandemic had caused a prompt decline in the tourism-related share performance, while the investment risks were increased. Similarly, Takyi and Bentum-Ennin (2021) discovered that the COVID-19 pandemic caused a significant decline in the African stock market performance. Harjoto and Rossi (2021) also found the negative impact of COVID-19 pandemic on the emerging stock markets rather than developed stock markets. Moreover, the negative impact is noticeable in small capitalisation and growth firms. However, a different impact of COVID-19 pandemic was revealed by the authors. The negative impact was stronger for the energy sector and financial sector in both emerging and developed markets, while the healthcare and communication sectors in emerging markets and information technology sector in developed markets had a positive impact. A similar negative significant effect of COVID-19 pandemic was also acknowledged by Elhini and Hamman (2021), but only in a few industries, such as communications, health, technology, consumer discretionary and staples. Meanwhile, the positive significant association of the COVID-19 pandemic and S\&P 500 Index was found in 
MANAGEMENT SCIENCES

Vol. 11, No. 3, 2021, E-ISSN: 2225-8329 @ 2021 HRMARS

the second period for communications, financial, industrial, utilities, and information technology industries.

Besides, Li et al (2021) found that COVID-19 pandemic increased connectedness on the total volatility of the $\mathrm{G} 20$ stock markets and demonstrated dynamic evolution characteristics of connectedness in different periods of the COVID-19 pandemic. Furthermore, Rehman et al. (2021) also found that G7 markets had high coherence with the number of confirmed COVID-19 cases and the number of deaths, but Canadian and Japanese markets demonstrated a marginal relation. By comparing the conventional and Islamic stock markets, Hassan et al (2021) found that COVID-19 pandemic had established identical volatility in both Islamic and conventional markets, whereas both markets were strongly correlated and move in the same manner during the pandemic period. However, unlike previous findings, Insaidoo et al. (2021) found that COVID-19 pandemic had no significant impact on the Ghana stock returns but it raised in the volatility of the Ghana stock returns. With that, the stock markets are likely to be negatively impacted by the COVID-19 pandemic as most investors will panic and react conservatively during that period.

A similar impact was also observed in the cryptocurrencies markets as most studies revealed that the COVID-19 pandemic had a significant impact on the cryptocurrency market in different research contexts. For example, Corbet et al (2020) found that Bitcoin did not react as an effective hedge or safe-haven benefit for the Chinese stock markets as the dynamic correlation was increased during the COVID-19 pandemic. Conlon and McGee (2020) concluded that the safe-haven characteristic was not offered by Bitcoin on the stock market in the COVID-19 pandemic period because they were moving in the same direction, and thus it could increase the portfolio risk. Conlon et al (2020) also revealed that Bitcoin and Ethereum did not provide the safe-haven property for most of the international stock markets as they would increase the downside risk on the portfolio. However, Tether could be a safe-haven destination for international stock markets.

Nevertheless, Corbet et al (2020) found that the large cryptocurrencies recorded a significant increase in the return and transaction volumes during the COVID-19 pandemic. Therefore, cryptocurrencies could provide an effective diversification benefit and also safehaven characteristic during the pandemic period. Corbet et al (2021) found that cryptocurrencies were potential safe-haven instruments in the COVID-19 pandemic as liquidity was significantly improved after the declaration of COVID-19 pandemic as a worldwide pandemic. Similarly, Melki and Nefzi (2021) revealed that Ethereum could provide a strong safe-haven property on the commodity market in pre- and during the COVID-19 pandemic period. However, Bitcoin only displayed a strong safe-haven property for the commodity market in the COVID-19 pandemic period, while Ripple only showed a weak safehaven characteristic for the foreign exchange market. In terms of return, Nguyen (2021) found that during the high uncertainty periods and during the COVID-19 pandemic, the return of Bitcoin was significantly affected by previous stock market returns. Besides, Mnif and Jarboui (2021) found that Bitcoin became less fractal but more efficient after the COVID-19 pandemic.

In Malaysia, different studies were conducted to examine the impact of COVID-19 pandemic on the financial markets. For example, Chia et al (2020) found that the daily new confirmed COVID-19 cases and deaths had an insignificant negative effect on the stock indices' returns, while the MCO had a significantly positive effect on the return of involved indices and foreign financial risks were adversely influenced on these returns. Lee et al. (2020a) found that the numbers of COVID-19 cases in Malaysia were likely to impact badly on the FBMKLCl index performance and all sectoral indices, except for the Real Estate Investment 
MANAGEMENT SCIENCES

Vol. 11, No. 3, 2021, E-ISSN: 2225-8329 @ 2021 HRMARS

Fund (REIT) index. The study also revealed that the Brent oil price and the volatility index were inclined to impact the Malaysian stock market performance. Besides, Lee et al. (2020b) also found that the majority of moving average rules could provide positive returns on banking stocks before the MCO and loan moratorium announcement dates. Therefore, the technical rules were an informative signal for an investment decision. Similar findings were also revealed by Lee and Jais (2021), whereas during the COVID-19 pandemic period, the moving average rule could provide a positive return in the Malaysian stock market.

Moreover, Ishak et al (2021) revealed that cyclical sectors, such as tourism, airlines, restaurants and transportation were impacted by the COVID-19 pandemic due to fear of society on the transmission of the virus during transaction with these companies. Meanwhile the non-cyclical industries, such as manufacturing, healthcare, and telecommunications could perform positive abnormal returns, as more transactions were shifted into the online medium. Furthermore, by using cross-countries data, Mubarok and Al-Arif (2021) further found that all Islamic indexes tended to decline because the COVID-19 pandemic inclined to impact current and future economic performances. Therefore, it is expected that the COVID19 pandemic could significantly affect the financial markets, no matter from the different context of studies, as reviewed in the previous section.

\section{Methodology}

In this study, five largest cryptocurrencies, except Tether, were selected to examine the comovement with FBMKLCl and MYRUSD. These five cryptocurrencies are Bitcoin, Ethereum, Binance, Cardano, and Ripple. The daily frequency dataset was spanned from May 2013 to July 2021 for Bitcoin, FBMKLCl, and MYRUSD, while other cryptocurrencies were assessed from their inception date until July 2021. The full dataset was divided into two sub-periods to separate the before and during COVID-19 pandemic. As the first positive COVID-19 case in Malaysia was declared on 25 January 2020 (Shah et al. 2020), therefore, the period before 28 January 2020 was categorised as before the COVID-19 period while starting on 28 January 2020 until July 2021 was categorised as the during COVID-19 period. The dataset of the study including the price of cryptocurrencies, FBMKLCl and MYRUSD, were downloaded from the websites of coinmarketcap.com and investing.com, respectively. However, due to the incomplete dataset on the website, Tether was excluded from this study and was replaced with Ripple, which is ranked as the sixth-largest cryptocurrency. According to coinmarketcap.com, the total market capitalisation of the cryptocurrencies was $\$ 1,931.2$ billion as of 18 August 2021. These five selected cryptocurrencies were accounted for approximately $73 \%$ of the overall cryptocurrencies market. The collected dataset for cryptocurrencies was then harmonised with the datasets of $\mathrm{FBMKLCl}$ and MYRUSD as the trading period of these two assets was only limited to weekdays. Therefore, the cryptocurrencies data for weekends were excluded to ensure the consistency of the datasets between cryptocurrencies and $\mathrm{FBMKLCl}$ and MYRUSD, and this was followed by the works of Klein et al. (2018) and Smales (2019). The daily returns of the dataset were calculated by using the capital gain yield formula $\left(R_{t}=\frac{\left(P_{t}-P_{t-1}\right)}{P_{t-1}}\right)$, where $R_{t}$ is the daily returns of cryptocurrencies, FBMKLCl, and MYRUSD series at time $t$; and $P_{t}$ and $P_{t-1}$ are the closing prices/rates of the series at time $t$ and $t-1$, respectively.

The dynamic conditional correlation of multivariate GARCH estimation (MGARCHDCC) was utilised to examine the time-varying pairwise conditional correlation or comovement between the return series of the selected cryptocurrencies together with $\mathrm{FBMKLCl}$ 
MANAGEMENT SCIENCES

Vol. 11, No. 3, 2021, E-ISSN: 2225-8329 @ 2021 HRMARS

and MYRUSD. MGARCH-DCC could provide a robust correlation series on the changes of the conditional correlation between two return series throughout the study period, as compared to conventional correlation, which only provided a correlation value for the entire study period. Moreover, MGARCH-DCC also provided the positive or negative direction together with the degree of correlation between two return series (Saiti and Noordin 2018). The complementation or substitution of correlation for the two return series could also be determined by using this method (Abdullah et al. 2016). In the estimation of MGARCH-DCC, the standard residuals of the return series were first estimated by using the univariate GARCH method, and this standard residual was used to calculate the time-varying conditional correlation by using the equation of $H_{t}=D_{t} R_{t} D_{t}$, where $H_{t}$ is the multivariate conditional covariance, $D_{t}$ is the conditional time-varying standardised residuals $\left(\varepsilon_{t}\right)$, and $R_{t}$ is the timevarying correlation matrix. Additionally, the MGARCH-DCC model can be characterised as $Q_{t}=(1-\alpha-\beta) \bar{Q}+\alpha \varepsilon_{t_{-} 1} \dot{\varepsilon}_{t-1}+\beta Q_{t-1}$, where $Q_{t}$ represents the time-varying conditional correlation of standardised residuals, $\bar{Q}$ represents the unconditional correlation of $\varepsilon_{t_{-}} \varepsilon_{t-1}$, and $a$ and $\beta$ represent the non-negative parameters of $a+\beta<1$. Lastly, the DCC linking the selected cryptocurrencies $\left(i^{\text {th }}\right)$ and FBMKLCl and MYRUSD $\left(j^{\text {th }}\right)$ is estimated using the equation of $p_{i j, t}=\frac{q_{i j, t}}{\left(\sqrt{q_{i, i}} \sqrt{q_{j j, t}}\right)}$, where $q_{i j}$ represents the elements of the $i^{\text {th }}$ and $j^{\text {th }}$ columns on the matrix $Q_{t}$. After the conditional correlation or co-movement of the assets were obtained from MGARCH-DCC, the independence t-test and non-parametric Mann-Whitney $U$ test were adopted to examine the differences between pre-COVID-19 and during the COVID-19 period.

\section{Results and Discussions}

The descriptive statistics of the involved return series is presented in Table 1 and it is divided into three panels. Panel A showed the mean and standard deviation of the return series for the full study period, while Panel $B$ and Panel $C$ provided the mean and standard deviation for the period before COVID-19 pandemic and during the COVID-19 pandemic. As shown in Panel A, all five selected cryptocurrencies can provide a positive daily return, whereby Binance was found to be the most profitable cryptocurrency with an average daily return of $0.96 \%$ and Bitcoin recorded the lowest average daily return $(0.35 \%)$ during the study period. However, negative daily return was reported for FBMKLCl and MYRUSD with $-0.0045 \%$ and $0.0156 \%$, respectively. By comparing the average daily return between the period before COVID-19 pandemic and during COVID-19, it showed that Bitcoin, Ethereum, and Cardano generated higher average daily returns during the COVID-19 period, while the average daily returns of Binance and Ripple were reduced during the COVID-19 pandemic. As affected by the COVID-19 pandemic, the average daily returns for FBMKLCl also decreased, while the negative average daily returns of the MYRUSD was improved. In terms of the standard deviation, Cardano, Binance, and Ripple were the three risky cryptocurrencies for the full study period and before and during COVID-19 pandemic period. 
INTERNATIONAL JOURNAL OF ACADEMIC RESEARCH IN ACCOUNTING, FINANCE AND MANAGEMENT SCIENCES

Vol. 11, No. 3, 2021, E-ISSN: 2225-8329 @ 2021 HRMARS

Table 1. Descriptive Statistics

\begin{tabular}{lllllll}
\hline & \multicolumn{2}{l}{ Full Period } & \multicolumn{2}{l}{ Before COVID-19 } & \multicolumn{2}{c}{ During COVID-19 } \\
\hline & Mean & $\begin{array}{l}\text { Standard } \\
\text { Deviation }\end{array}$ & Mean & $\begin{array}{l}\text { Standard } \\
\text { Deviation }\end{array}$ & Mean & $\begin{array}{l}\text { Standard } \\
\text { Deviation }\end{array}$ \\
\hline Bitcoin & 0.3455 & 4.6059 & 0.3141 & 4.5988 & 0.4852 & 4.6410 \\
Ethereum & 0.5478 & 6.6456 & 0.5314 & 6.8724 & 0.5959 & 5.9396 \\
Binance & 0.9559 & 8.1171 & 1.0505 & 8.3193 & 0.8008 & 7.7828 \\
Cardano & 0.4634 & 8.7822 & 0.3294 & 9.7731 & 0.6675 & 7.0189 \\
Ripple & 0.5858 & 7.9629 & 0.6048 & 8.0170 & 0.5043 & 7.7375 \\
FBMKLCI & -0.0045 & 0.6852 & -0.0037 & 0.5632 & -0.0080 & 1.0722 \\
MYRUSD & -0.0156 & 0.4142 & -0.0169 & 0.4365 & -0.0094 & 0.2959 \\
\hline
\end{tabular}

Table 2 presents the unconditional volatilities of each return series and unconditional correlation between the selected cryptocurrencies and FBMKLCl or MYRUSD. Amongst all return series, Cardano had the highest volatilities (8.7530), followed by Ripple (7.9753) and Binance (7.5399), while FBMKLCl and MYRUSD reported the lowest unconditional volatilities ( 0.6818 and 0.4119 , respectively). Panel $A$ in Table 2 also demonstrated the unconditional correlation between cryptocurrencies and $\mathrm{FBMKLCl}$ and it showed that Bitcoin, Ethereum, and Ripple had a negative unconditional correlation with $\mathrm{FBMKLCl}$, which indicated that these three cryptocurrencies could be an effective hedge instrument for FBMKLCl. Meanwhile, Cardano and Binance had a positive unconditional correlation with FBMKLCl. Besides, the unconditional correlation of the cryptocurrencies and MYRUSD in Panel B showed that only Ethereum possessed the hedging characteristic over MYRUSD, as it was the only cryptocurrency that had a negative unconditional correlation with MYRUSD while the other four cryptocurrencies had a positive unconditional correlation with MYRUSD.

Table 2. Unconditional Correlation and Volatilities

\begin{tabular}{llll}
\hline & FBMKLCl & MYRUSD & Unconditional Volatility \\
\hline Bitcoin & -0.0098 & 0.0026 & 4.6256 \\
Ethereum & -0.0085 & -0.0069 & 6.3595 \\
Binance & 0.0206 & 0.0389 & 7.5399 \\
Cardano & 0.0308 & 0.0447 & 8.7530 \\
Ripple & -0.0088 & 0.0286 & 7.9753 \\
Unconditional Volatility & 0.6818 & 0.4119 & \\
\hline
\end{tabular}

Figure 1 and Figure 2 illustrate the time-varying conditional correlation or comovement between the five selected cryptocurrencies with FBMKLCl and MYRUSD, respectively. In Figure 1, the conditional correlation or co-movement of the cryptocurrencies and $\mathrm{FBMKLCl}$ showed that the cryptocurrencies tended to have a negative co-movement with FBMKLCl during early period, especially for Bitcoin, Ripple, and Ethereum, while Cardano and Binance showed a positive co-movement with $\mathrm{FBMKLCl}$ since their inception. All five cryptocurrencies possessed a greater correlation with $\mathrm{FMBKLCl}$ in 2018, especially after the $14^{\text {th }}$ general election in May 2018, whereby the Bitcoin start turned to positively correlated with $\mathrm{FBMKLCl}$. However, the correlation of the five cryptocurrencies reached its peak in November 2018 and fell after that, whereas Bitcoin, Ripple, and Ethereum turned negative in January 2019. The co-movement of all five cryptocurrencies and FBMKLCI was enhanced after the COVID-19 pandemic outbreak, which started in January 2020, whereas, the first 
MANAGEMENT SCIENCES

Vol. 11, No. 3, 2021, E-ISSN: 2225-8329 @ 2021 HRMARS

confirmed cases were declared on 25 January 2020. The co-movement of these cryptocurrencies and $\mathrm{FBMKLCl}$ continued to increase after that but began to fall in November 2020; Ripple and Ethereum turned negative in April 2021 but reversed to positive again in May 2021. Therefore, Figure 1 shows that the co-movement of the five selected cryptocurrencies and $\mathrm{FBMKLCl}$ was greatly improved during the early COVID-19 pandemic period, especially for Bitcoin and Ripple, which had a negative correlation before the pandemic, but the movement was reduced after November 2020. This provided an intuition that the cryptocurrencies might not be a better investment choice to hedge the stock market investment in the pandemic period as the co-movement between them was greatly improved in the pandemic period.

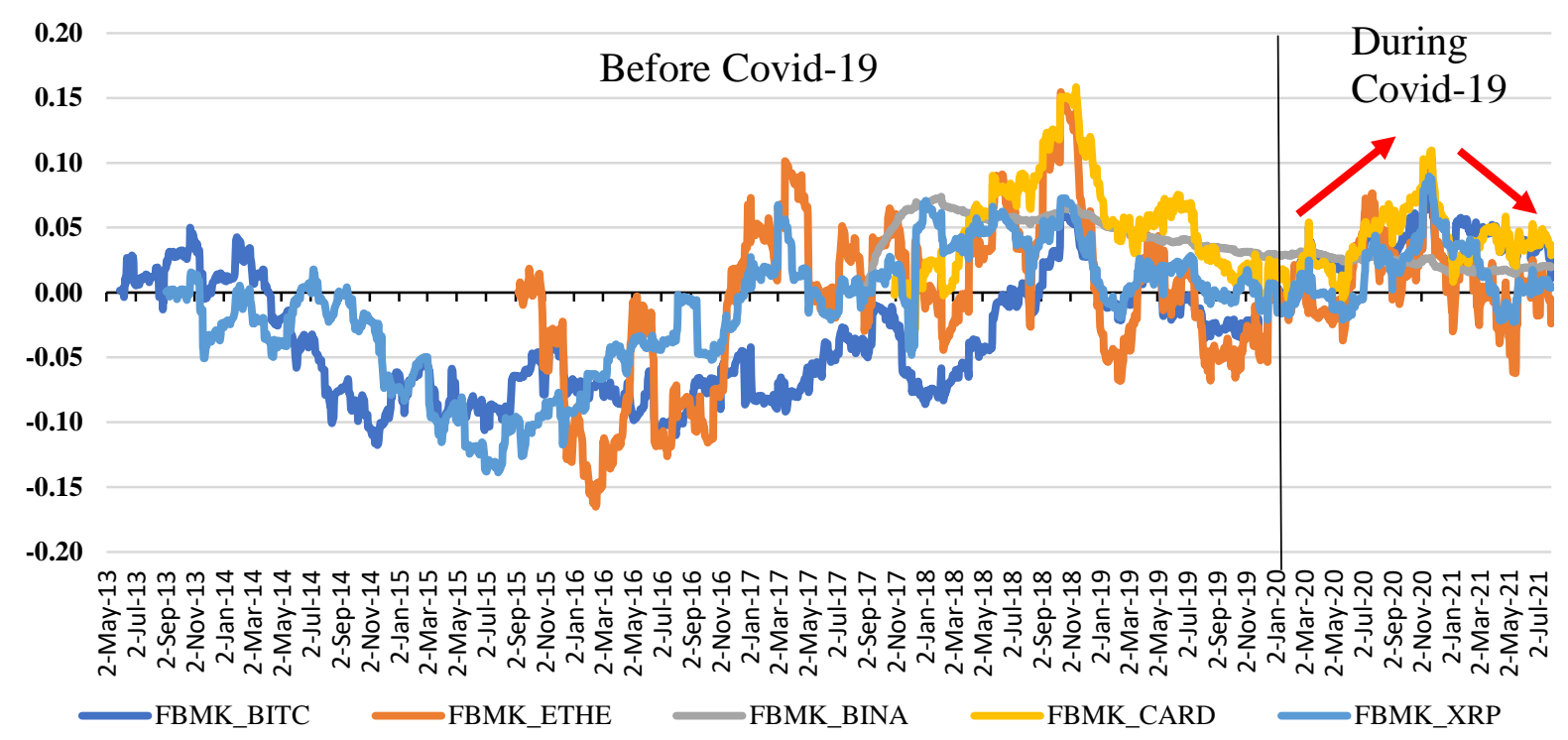

Figure 1. Conditional Correlation between Cryptocurrencies and FBMKLCl

Figure 2 shows the time-varying conditional correlation of the five selected cryptocurrencies and MYRUSD. Unlike Figure 1, Ripple showed a positive co-movement with MYRUSD since its inception. However, Ethereum had the most volatile conditional correlation with MYRUSD as it had a negative co-movement at the beginning period and turned to positive after March 2017. But, again changed to negative in March 2018 and turned to positive in August 2018 before it reversed to negative co-movement together with the other four cryptocurrencies in May 2019. Bitcoin also showed a negative co-movement with MYRUSD for most of the period, except for a short period from September 2018 until March 2019. Same as Cardano, whereby it also had a positive co-movement with MYRUSD since its inception except for May 2019 until November 2019. Interestingly, Binance did not show a similar trend with other cryptocurrencies as it had a stable and consistent positive comovement with MYRUSD throughout the period. In general, Figure 2 shows that all cryptocurrencies moved in a similar co-movement except for Binance, especially those which started from November 2018 to July 2021. The co-movement between the selected cryptocurrencies and MYRUSD was greatly improved after the COVID-19 pandemic outbreak, except for Binance, which remained a stable trend. Therefore, the cryptocurrencies might not react as an ideal instrument that could be used to hedge foreign exchange investment. 


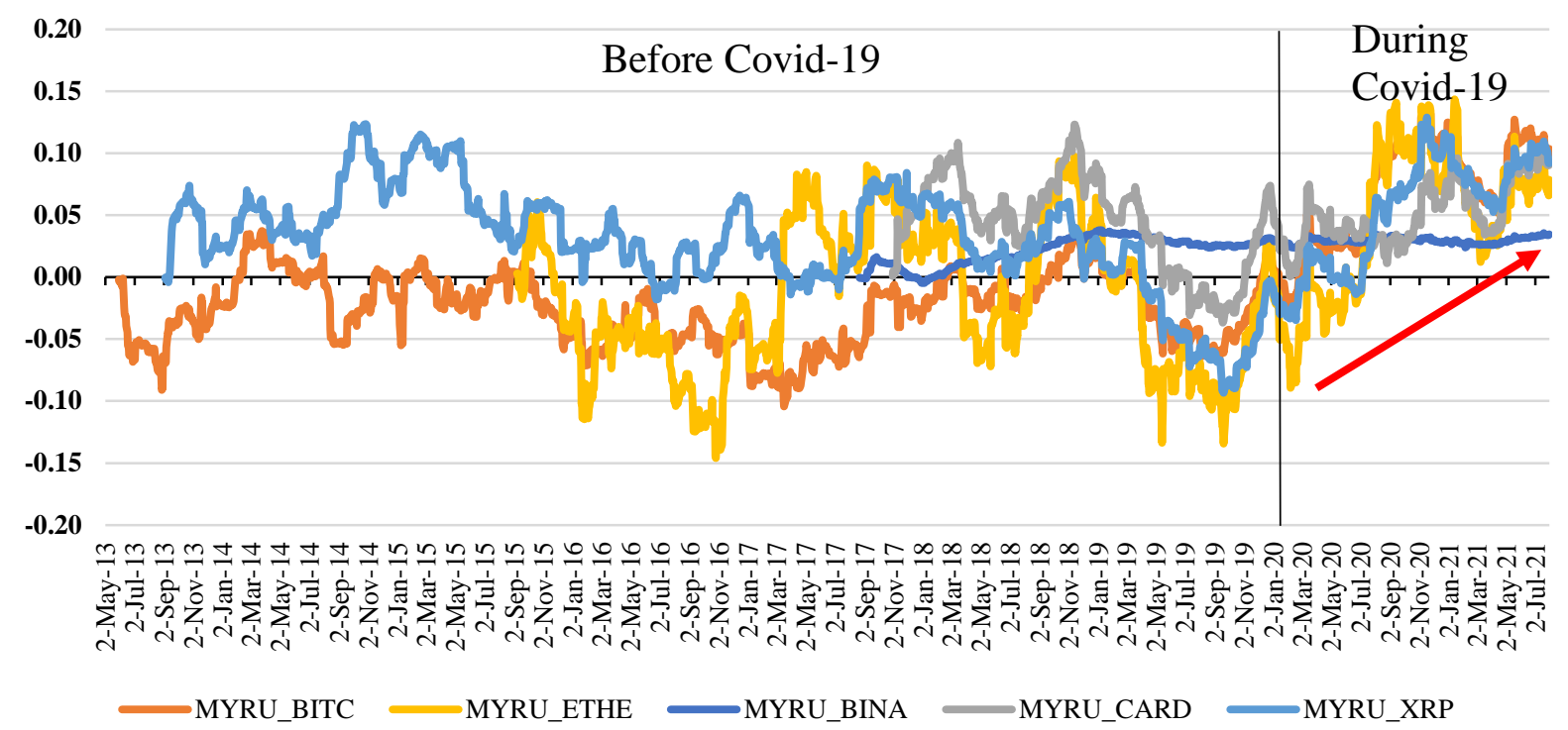

Figure 2. Conditional Correlation between Cryptocurrencies and MYRUSD

Table 3 presents the descriptive statistics of the conditional correlation of these return series, to provide a clear picture of the movement on the conditional correlation between the five selected cryptocurrencies and FBMKLCI and MYRUSD, especially before the COVID-19 pandemic and during the COVID-19 pandemic period. The table showed that Bitcoin, Ethereum, and Ripple had a negative average daily conditional correlation with FBMKLCI and the average daily conditional correlation turned to positive in the COVID-19 pandemic period. However, the average daily conditional correlation of Binance and Cardano was reduced in the COVID-19 pandemic period, which was from 0.0484 and 0.0521 to 0.0226 and 0.0407 , respectively. This indicated that the conditional correlation of Binance and Cardano was weak in the COVID-19 pandemic period, but the correlation was strengthened for Bitcoin, Ethereum, and Ripple in the same COVID-19 pandemic period.

A similar scenario was also observed from the conditional correlation between the cryptocurrencies and MYRUSD, whereby the average daily conditional correlation of the cryptocurrencies and MYRUSD was strengthened in the COVID-19 pandemic period. Unlike FBMKLCl, only Bitcoin (-0.0260) and Ethereum (-0.0185) had a negative average daily conditional correlation with MYRUSD in the period before COVID-19, while the other three cryptocurrencies had a positive average daily conditional correlation before COVID-19. However, the average daily conditional correlation of all five cryptocurrencies and MYRUSD was stronger in the COVID-19 pandemic period. Therefore, this implied that the conditional correlation of the cryptocurrencies and MYRUSD was improved during the COVID-19 pandemic period. 
MANAGEMENT SCIENCES

Vol. 11, No. 3, 2021, E-ISSN: 2225-8329 ๔ 2021 HRMARS

Table 3. Conditional Correlation before and during COVID-19 pandemic

\begin{tabular}{|c|c|c|c|c|c|c|}
\hline & \multicolumn{3}{|c|}{ Before COVID-19 } & \multicolumn{3}{|c|}{ During COVID-19 } \\
\hline & Mean & Min. & Max. & Mean & Min. & Max. \\
\hline \multicolumn{7}{|c|}{ Cryptocurrencies and FBMKLCl } \\
\hline Bitcoin & -0.0400 & -0.1177 & 0.0621 & 0.0350 & -0.0137 & 0.0757 \\
\hline Ethereum & -0.0076 & -0.1651 & 0.1544 & 0.0115 & -0.0622 & 0.1030 \\
\hline Binance & 0.0484 & 0.0012 & 0.0740 & 0.0226 & 0.0144 & 0.0347 \\
\hline Cardano & 0.0521 & -0.0306 & 0.1584 & 0.0407 & -0.0055 & 0.1097 \\
\hline Ripple & -0.0163 & -0.1387 & 0.0727 & 0.0155 & -0.0226 & 0.0894 \\
\hline \multicolumn{7}{|c|}{ Cryptocurrencies and MYRUSD } \\
\hline Bitcoin & -0.0260 & -0.1044 & 0.0398 & 0.0708 & -0.0275 & 0.1322 \\
\hline Ethereum & -0.0185 & -0.1458 & 0.0973 & 0.0477 & -0.0893 & 0.1436 \\
\hline Binance & 0.0212 & -0.0049 & 0.0381 & 0.0296 & 0.0236 & 0.0355 \\
\hline Cardano & 0.0431 & -0.0367 & 0.1231 & 0.0518 & 0.0007 & 0.1072 \\
\hline Ripple & 0.0296 & -0.0933 & 0.1234 & 0.0550 & -0.0347 & 0.1290 \\
\hline
\end{tabular}

Notes: Max. represents the maximum value and Min. represents the minimum value.

Figure 1 and Figure 2 together with Table 3 demonstrated that the co-movement of the cryptocurrencies with FBMKLCl and MYRUSD was likely strengthened during the COVID19 pandemic period. The independence t-test and non-parametric Mann-Whitney $U$ test were further utilised to examine the significant differences of the co-movement of cryptocurrencies with FBMKLCl and MYRUSD before and during the COVID-19 pandemic period and results are shown in Table 4. Panel A showed that the co-movement of all five cryptocurrencies with FBMKLCl before the COVID-19 pandemic period had a significant difference during the COVID-19 pandemic period. This proved that COVID-19 pandemic had significantly impacted the co-movement of cryptocurrencies and $\mathrm{FBMKLCl}$, but in a different direction. Specifically, the COVID-19 pandemic strengthened the co-movement of Bitcoin, Ethereum, and Ripple with FBMKLCl, while the COVID-19 pandemic significantly weakened the co-movement between Binance and Cardano with $\mathrm{FBMKLCl}$. Therefore, this result suggested that the stock market investment can only be hedged by investing in Binance and Cardano in the pandemic period as the co-movement was reduced during the period. The findings of Bitcoin, Ethereum, and Ripple were consistent with Corbet et al (2020), Conlon et al (2020), and Conlon and McGee (2020) who also found a similar property on cryptocurrencies.

In the foreign exchange market, the co-movement between all five cryptocurrencies with MYRUSD was strengthened after the COVID-19 pandemic period, as the independent ttest and Mann-Whitney $U$ test showed significant results. This indicated that the hedging and/or safe-haven characteristics on foreign exchange investment were not provided by all five cryptocurrencies in the pandemic period and this supported earlier studies that also found similar findings in another context, such as Corbet et al (2020); Conlon et al (2020); and Conlon and McGee (2020). However, the findings were not consistent with Corbet et al. (2020); Corbet et al (2021), who concluded that cryptocurrencies could be a safe-haven destination for the other financial instruments in the pandemic period. Overall, the results provided robust evidence on the impact of COVID-19 pandemic on the co-movement between the five selected cryptocurrencies with FBMKLCI and MYRUSD as the co-movement of these series was significantly different as between the period before and during the COVID- 
INTERNATIONAL JOURNAL OF ACADEMIC RESEARCH IN ACCOUNTING, FINANCE AND MANAGEMENT SCIENCES

Vol. 11, No. 3, 2021, E-ISSN: 2225-8329 @ 2021 HRMARS

19 pandemic, although a different direction was observed for Binance and Cardano with FBMKLCI.

Table 4. Comparison before and during COVID-19 by using independence t-test

\begin{tabular}{|c|c|c|c|c|c|c|}
\hline & $\begin{array}{l}\text { Before } \\
\text { COVID-19 }\end{array}$ & $\begin{array}{l}\text { During } \\
\text { COVID-19 }\end{array}$ & Indepen & nce t-test & $\begin{array}{l}\text { Mann-Whitney } \\
\text { U Test }\end{array}$ & \\
\hline & Mean & Mean & $\begin{array}{l}\text { Mean } \\
\text { Diff. }\end{array}$ & Sig. & Sig. & Note \\
\hline \multicolumn{7}{|c|}{ Cryptocurrencies and FBMKLCI } \\
\hline Bitcoin & -0.0400 & 0.0350 & -0.0750 & 0.0000 & 0.0000 & Sig. Diff \\
\hline Ethereum & -0.0076 & 0.0115 & -0.0191 & 0.0000 & 0.0000 & Sig. Diff \\
\hline Binance & 0.0484 & 0.0226 & 0.0258 & 0.0000 & 0.0000 & Sig. Diff \\
\hline Cardano & 0.0521 & 0.0407 & 0.0114 & 0.0000 & 0.0190 & Sig. Diff \\
\hline Ripple & -0.0163 & 0.0155 & -0.0318 & 0.0000 & 0.0000 & Sig. Diff \\
\hline \multicolumn{7}{|c|}{ Cryptocurrencies and MYRUSD } \\
\hline Bitcoin & -0.0260 & 0.0708 & -0.0968 & 0.0000 & 0.0000 & Sig. Diff \\
\hline Ethereum & -0.0185 & 0.0477 & -0.0662 & 0.0000 & 0.0000 & Sig. Diff \\
\hline Binance & 0.0212 & 0.0296 & -0.0083 & 0.0000 & 0.0000 & Sig. Diff \\
\hline Cardano & 0.0431 & 0.0518 & -0.0087 & 0.0000 & 0.0000 & Sig. Diff \\
\hline Ripple & 0.0296 & 0.0550 & -0.0254 & 0.0000 & 0.0000 & Sig. Diff \\
\hline
\end{tabular}

Notes: Mean Diff. represents the mean differences, Sig. represents the $p$-value and Sig. Diff represents a significant difference.

\section{Conclusions and Implications}

This study was conducted to examine the impact of COVID-19 pandemic on the co-movement between five selected cryptocurrencies with the Malaysian stock index, FBMKLCl and currency rate of MYRUSD. The findings of the study showed that COVID-19 had a significant impact on the co-movement of the return series between cryptocurrencies with $\mathrm{FBMKLCl}$ and also MYRUSD as the co-movement of these return series during the COVID-19 pandemic period was significantly different from the co-movement before the pandemic. The COVID-19 pandemic strengthened the co-movement of these series as the conditional correlation was improved in the pandemic period, except for Binance and Cardano with $\mathrm{FBMKLCl}$, whereby the conditional correlation was reduced during the pandemic period. These findings suggested that the cryptocurrencies were not an effective hedging instrument during the COVID-19 pandemic period because the conditional correlation was increased during this period. However, both Binance and Cardano showed opposite findings, whereby both cryptocurrencies may provide marginal hedging or safe-haven features for the Malaysian stock market.

The findings provided important implications to relevant parties, such as investors and fund managers as the cryptocurrencies were not an effective instrument for them to hedge the stock market risk and foreign exchange investment in the COVID-19 pandemic period. Therefore, they should find other financial instruments that provide a better hedging characteristic over the stock market and foreign exchange investment during the pandemic period. However, investors and fund managers could invest in Binance and Cardano to hedge their stock market investment during the COVID-19 pandemic period as the co-movement of these two cryptocurrencies significantly reduced during this pandemic period. Lastly, market 
MANAGEMENT SCIENCES

Vol. 11, No. 3, 2021, E-ISSN: 2225-8329 @ 2021 HRMARS

regulators and authorities should be alert with these findings as the relevant policy and rules should be introduced to establish a more sustainable investment environment for all parties.

Some limitations existed in this study. This study only employed MGARCH-DCC to examine the time-varying conditional correlation between the cryptocurrencies with stock market index and foreign exchange rate in Malaysia. Therefore, future studies are suggested to adopt other time-series econometric methods to better examine the property of hedge and/or safe-haven of the cryptocurrency. Besides, the author(s) could also include other financial instruments like commodity prices to provide more comprehensive results on the co-movement between the cryptocurrencies on other financial instruments during the COVID-19 pandemic period. Moreover, the inclusion of more developing markets or comparing developed and developing markets in the study could also provide more robust results as COVID-19 pandemic may impact the co-movement differently.

\section{References}

Abdullah, A. M., Saiti, B., \& Masih, M. (2016). The impact of crude oil price on Islamic stock indices of South East Asian countries: Evidence from MGARCH-DCC and wavelet approaches. Borsa Istanbul Review, 16(4), 219-232.

Chen, M-H., Jang, S(S)., \& Kim, W. G. (2007). The impact of the SARS on Taiwanese hotel stock performance: An event-study approach. Hospitality Management, 26, 200-212.

Chensney, M., Reshetar, G., \& Karaman, M. (2011). The impact of terrorism on financial markets: An Empirical study. Journal of Banking and Finance, 35, 253-267.

Chia, R. C-J., Liew, V, K-S., \& Rowland, R. (2020). Daily New COVID-19 Cases, the Movement Control Order, and Malaysian Stock Market Returns. International Journal of Business and Society, 21(2), 553-568.

Conlon, T., \& McGee, R. (2020). Safe haven or risky hazard? Bitcoin during the COVID-19 bear market. Finance Research Letters, 35, 101607.

Conlon, T., Corbet, S., \& McGee, R. J. (2020). Are cryptocurrencies a safe haven for equity markets? An international perspective from the COVID-19 pandemic. Research in International Business and Finance, 54, 101248.

Corbet, S., Hou, Y(G), Hu, Y., Larkin, C., Lucey, B., \& Oxley, L. (2021). Cryptocurrency liquidity and volatility interrelationships during the COVID-19 pandemic. Finance Research Letter, 102137, In Press, Corrected Proof.

Corbet, S., Hou, Y(G), Hu, Y., Larkin, C., Lucey, B., \& Oxley, L. (2020). Any port in a storm: Cryptocurrency safe-havens during the COVID-19 pandemic. Economics Letters, 194, 109377.

Corbet, S., Larkin, C., \& Lucey, B. (2020). The contagion effects of the COVID-19 pandemic: Evidence from gold and cryptocurrencies. Finance Research Letters, 35, 101554.

Elhini, M., \& Hammam, R. (2021). The impact of COVID-19 on the standard and poor 500 index sectors: a multivariate generalized autoregressive conditional heteroscedasticity model. Journal of Chinese Economic and Foreign Trade Studies, 14(1), 18-43.

Feng, Y., \& Li, X. (2021). Causal estimation of COVID-19 and SARS on China's stock market: evidence from a time series counterfactual prediction. Economics Research EKONOMSKA ISTRAZIVANJA, https://doi.org/10.1080/1331677X.2021.1910533

Ferreira, S., \& Karali, B. (2015). Do Earthquakes Shake Stock Markets? PLoS ONE, 10(7), e0133319. 
MANAGEMENT SCIENCES

Vol. 11, No. 3, 2021, E-ISSN: 2225-8329 ๔ 2021 HRMARS

Harjoto, M. A., \& Rossi, F. (2021). Market reaction to COVID-19 pandemic: evidence from emerging markets. International Journal of Emerging Market, Vol. ahead-of-print No. ahead-of-print. https://doi.org/10.1108/IJOEM-05-2020-0545

Hassan, M. B., Mahi, M., Hassan, M. K., \& Bhuiyan, A. B. (2021). Impact of COVID-19 pandemic on stock markets: Conventional vs Islamic indices using wavelet-based multi-timescales analysis. North American Journal of Economics and Finance, 58, 101504.

He, Q., Liu, J., Wang, S., \& Yu, J. (2020). The impact of COVID-19 on stock markets. Economic and Political Studies, 8(3), 275-288.

Insaidoo, M., Arthur, L., Amoako, S., \& Andoh, F. K. (2021). Stock market performance and COVID-19 pandemic: evidence from a developing economy. Journal of Chinese Economic and Foreign Trade Studies, 14(1), 60-73.

Ishak, N., Shahar, H. K., \& Jiun, R. C. C. (2021). Cyclical Industries' Stock Performance Reaction during COVID-19: A Systematic Literature Review, Jurnal Ekonomi Malaysia, 55(1), 147158.

Klein, T., Thu, P. H., \& Walther, T. (2018). Bitcoin is not the New Gold - A comparison of volatility, correlation and portfolio performance. International Review of Financial Analysis, 59, 105-116.

Lahmiri, S., \& Bekiros, S. (2020). The impact of COVID-19 pandemic upon stability and sequential irregularity of equity and cryptocurrency markets. Chaos, Solitons and Fractals, 138, 109936.

Lee, K. Y-M., Jais, M., \& Chan, C-W. (2020a). Impact of COVID-19: Evidence from Malaysian Stock Market. International Journal of Business and Society, 21(2), 607-628.

Lee, K., Zaidi, N. S., \& Chan, C. W. (2020b). Technical Analysis and Malaysian Banking Sector during COVID-19 Pandemic. UNIMAS Review of Accounting and Finance, 4(1), 41-46.

Lee, K. Y. M., \& Jais, M. (2021). Effectiveness of Moving Average Rules during COVID-19 Pandemic: Evidence from Malaysian Stock Market. Jurnal Ekonomi Malaysia, 55(1), 8798.

Li, Y., Zhuang, X., Wang, J., \& Dong, Z. (2021). Analysis of the impact of COVID-19 pandemic on G20 stock markets. North American Journal of Economics and Finance, 58, 101530.

Liew, V., K-S. (2020). The effect of novel coronavirus pandemic on tourism share prices. Journal of Tourism Futures, Vol. ahead-of-print No. ahead-of-print. https://doi.org/10.1108/JTF-03-2020-0045

Melki, A., \& Nefzi, N. (2021). Tracking safe haven properties of cryptocurrencies during the COVID-19 pandemic: A smooth transition approach. Finance Research Letters, 102243, In Press, Corrected Proof.

Mnif, E., \& Jarboui, A. (2021). COVID-19, bitcoin market efficiency, heard behaviour. Review of Behavioural Finance, 13(1), 69-84.

Mubarok, F., \& Al-Arif, M. N. R. (2021). Pandemic Attack and Islamic Stocks Index: A Cross Country Analysis. Jurnal Ekonomi Malaysia, 55(1), 27-37.

Nguyen, K. Q. (2021). The correlation between the stock market and Bitcoin during COVID-19 and other uncertainty periods. Finance Research Letter, 102284, In Press, Corrected Proof.

Rehman, M. U., Kang, S. H., Ahmad, N., \& Vo, X. V. (2021). The impact of COVID-19 on the G7 stock markets: A time-frequency analysis. North American Journal of Economics and Finance, 58, 101526. 
Rubbaniy, G., Polyzos, S., Rizvi, S. K. A., \& Tessema, A. (2021). COVID-19, Lockdowns and herding towards a cryptocurrency market-specific implied volatility index. Economics Letters, 207, 110017.

Saiti, B., \& Noordin, N. H. (2018). Does Islamic equity investment provide diversification benefits to conventional investors? Evidence from the multivariate GARCH analysis. International Journal of Emerging Markets, 13(1), 267-289.

Scholtens, B., \& Voorhorst, Y. (2013). The Impact of Earthquakes on the Domestic Stock Market. Earthquake Spectra, 29(1), 325-337.

Shah, A. U. M., Safri, S. N. A., Thevadas, R., Noordin, N. K., Rahman, A. A., Sekawi, Z., Ideris, A., \& Sultan, M. T. H. (2020). COVID-19 outbreak in Malaysia: Actions taken by the Malaysian government. International Journal of Infectious Diseases, 97, 108-116.

Smales, L. A. (2019). Bitcoin as a safe haven? Is it even worth considering? Finance Research Letters, 30, 385-393.

Takyi, P. O., \& Bentum-Ennin, I. (2021). The impact of COVID-19 on stock market performance in Africa: A Bayesian structural time series approach. Journal of Economics and Business, $115,105968$.

Tavor, T., \& Teitler-Regev, S. (2019). The impact of disaster and terrorism on the stock market. Jamba - Journal of Disaster Risk Studies, 11(1), a534.

Umar, Z., Jareno, F., \& Gonzalez, M. D. I. O. (2021). The impact of COVID-19-related media coverage on the return and volatility connectedness of cryptocurrencies and fiat currencies. Technological Forecasting and Social Change, 172, 121025. 